\title{
Levels of vibration transmitted to the operator of the tractor equipped with front axle suspension
}

\author{
Daniele Pochi, Roberto Fanigliulo, Laura Fornaciari, Gennaro Vassalini, Marco Fedrizzi, \\ Gino Brannetti, Cesare Cervellini
}

\author{
Consiglio per la ricerca e la sperimentazione in agricoltura, CRA-ING Unità di ricerca per \\ I'ingegneria agraria, Agricultural Engineering Research UnitMonterotondo (Rome), Italy
}

\begin{abstract}
In recent years the comfort and the preservation of the health of the operators became central issues in the evolution of agricultural machinery and led to the introduction of devices aimed at improving working conditions. Thereby, for instance, the presence of air conditioner, soundproof cab and driver seat suspension became normal on agricultural tractors. The vibrations are one of the most complex issues to deal with, being determined by the characteristics and interaction of elements such as tyres, axles, mainframe, cab and seat suspension. In this respect, manufacturers are trying to improve their products, even integrating these elements with new devices such as the suspension on the front axle of the tractor, aimed at reducing the level of vibrations during the transfers at high speed. One of these underwent tests at CRA-ING. Since its purpose is to reduce the level of vibration transmitted to the driver, their measurements in different points of the tractor and in different operating conditions, were compared in order to evaluate the effectiveness of the device, expressed as time of exposure. The suspension system of the front axle is designed to absorb the oscillations (especially pitching) determined by irregularities in the road surface, allowing an increased control of the vehicle at high speed, as demonstrated by the test results and confirmed by the driving impressions outlined by the operator. The action of the device under these conditions results in an increase of the exposure time, important fact because of the relevance of the road transfer operations of tractors with mounted implements or trailers to tow and of the tendency to increase the speed limit for the road tractors (in Germany were brought to $50 \mathrm{~km} \mathrm{~h}^{-1}$ for several
\end{abstract}

Correspondence: Daniele Pochi, Unità di ricerca per l'ingegneria agraria, Via della Pascolare, 16, 00015 Monterotondo (Rome), Italy.

Tel. +39.06 .90675232 - Fax: +39.06 .90625591 .

E-mail: daniele.pochi@entecra.it

Keywords: vibrations, tractor suspensions, comfort, health protection.

Contributions: the authors contributed equally.

Conflict of interests: the authors declare no potential conflict of interests.

(C) Copyright D. Pochi et al., 2013

Licensee PAGEPress, Italy

Journal of Agricultural Engineering 2013; XLIV(s2):e151

doi:10.4081/jae.2013.s2.e151

This article is distributed under the terms of the Creative Commons Attribution Noncommercial License (by-nc 3.0) which permits any noncommercial use, distribution, and reproduction in any medium, provided the original author(s) and source are credited. years). The action just described is less evident with increasing irregularity of the road surface and with the decrease of the travel speed. Nevertheless, in such conditions, the device appears to positively work along the other directions, in particular in the Z-axis, improving the action of the suspension of the driver seat.

\section{Introduction}

Since several years, the technological evolution of agricultural machinery focused the attention, beside the operative performances, on the aspects of comfort and health safe of the operator, introducing devices and measures aimed at improving the working conditions. Thereby, for example, the presence of the air conditioning and soundproofing systems in the cab of the tractor became normal, as well as driver's seats fitted with shock absorbers effective against the vibrations induced by the execution of the agricultural works (Ragni et al., 1999). Vibrations are one of the most important and complex problem to deal with, being determined by the characteristics and the interaction of different elements such as tires, axles, main frame, cab and driver seat (Fornaciari et al., 2008).

In relatively recent times, modern tractors, in addition to the suspension seat, are sometimes equipped with other devices aimed at improving the comfort of the driver, such as the front axle suspension and systems capable of changing the setting of the cockpit.

This paper reports the results of tests carried out on a tractor equipped with suspension of the front axle during transfer operations on different surfaces in order to observe its effect on the level of vibration at the driver seat.

\section{Materials and methods}

Tractor - The tests were conducted on a tractor of medium-high power $(147 \mathrm{~kW})$ suitable for the multiple farm needs and with a high level of comfort and ergonomics for the operator (Nuccitelli and Ragni, 1993). Considering the subject of the tests, beyond the driver seat with pneumatic suspension (in which a rubber cylinder containing pressurized air works as a spring), the front axle of the tractor was provided with an original suspension (Figure 1).

The front axle is hinged to the body of the tractor by means of arms, which allow the longitudinal or transverse oscillation and damping by means of the combined action of two hydraulic cylinders and of two nitrogen accumulators mounted in series. The oil leaking from the cylinders during the compression phases is received by the nitrogen accumulators which absorb the shocks.

The use of the suspended axle is recommended during road transfer, where it help to reduce the danger represented by bumps at high 

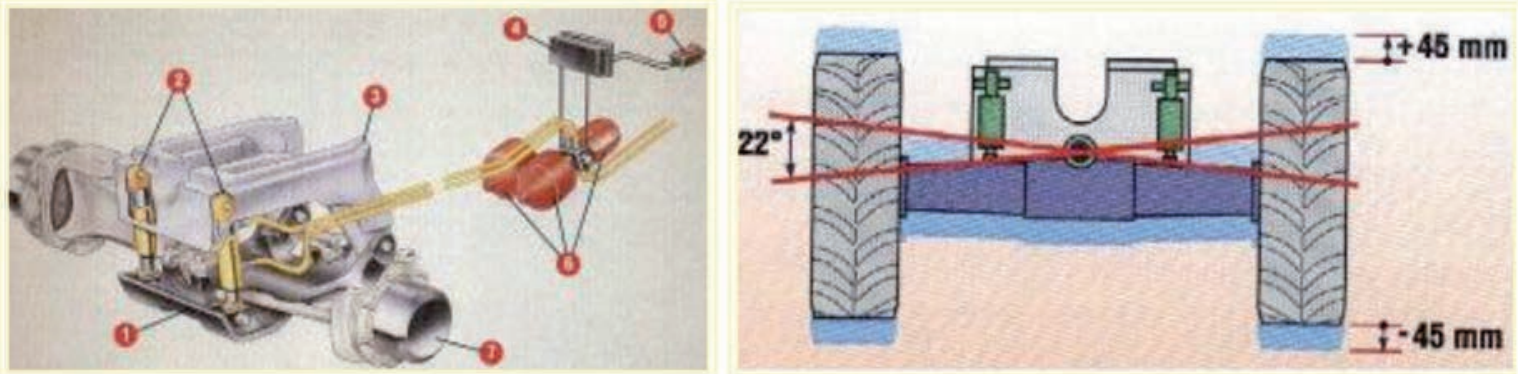

Figure 1. Left: scheme of the hydraulic-pneumatic suspension of the fron axle 1) mobile structure hinged to the main frame of the tractor; 2) doubleacting hydraulic cylinders; 3) tractor main frame; 4) electronic controll unit; 5) on-off switch; 6) nitrogen accumulators; 7) Front axle. Right: Maximum amplitude of the oscillation allowed by the hydraulic cylinders.

travel speed. Under field conditions, its effectiveness is less evident and, at any rate, it is automatically disconnected whit the differential is locked.

Instruments - The instrumental chain use in the tests consisted of: two 6-channels signal conditioners Brüel \& Kjær mod. 'Nexus'; 8-channel digital recorder DAT-Herm;

signal acquisition and processing system Brüel \& Kjær, mod. Pulse; calibrator for accelerometers Brüel \& Kjær, type 4294;

tri-axial accelerometer adapted for driver seat Brüel \& Kjær, type 4322 ;

- $\quad$ two tri-axial accelerometers Brüel \& Kjær, type 4321, positioned on the cab floor and on the tractor mainframe

Methods - As previously said, the tests aimed at verifying the presence of effects of the introduction of the front axle suspension on the level of vibration. From this point of view, the basic parameter to measure, is the acceleration, a, expressed in $\mathrm{ms}^{-2}$. As the effects of the vibrations depend on the frequency of the accelerations, these must be weighted by means of suitable filters, according to the standard ISO 2631-1:1997, and the Italian law (D.Lgs 81/2008) for the measurement of the levels of whole body vibrations transmitted to the operator by the driver seat (Scarlett et al., 2007). The accelerometers were positioned with the purpose of measuring the vibration levels in correspondence of the main elements of the system that transmit the vibrations themselves. Therefore, an accelerometer was placed on the driver's seat, as the remaining two were placed, respectively, on the cab floor and on the main frame of the tractor, on the same vertical line of the first. The accelerometers were oriented accordingly to the requirements of the standard ISO 2631-1:1997, as described in the Figure 2.

The weighting filters are calculated as a function of the human body sensitiveness to the acceleration in the different sampling frequencies and provide an acceleration value called frequency weighted acceleration, $\mathrm{a}_{\mathrm{w}}$,

$a_{w}=\left[\frac{1}{\mathrm{~T}} \int_{0}^{\mathrm{T}} a_{w}^{2}(t) d t\right]^{\frac{1}{2}}$

where:

$\mathrm{a}_{\mathrm{w}}(\mathrm{t})$ is the measured value of the acceleration; $\mathrm{T}$ is the acquisition time interval in seconds.

The three components of the acceleration along the $\mathrm{X}, \mathrm{Y}$ and $\mathrm{Z}$ axes are simultaneously measured and the resultant vector of the acceleration $\mathrm{a}_{\mathrm{v}}$ is provided by the relation:

$$
a_{v}=\left(k_{x}^{2} a_{w x}^{2}+k_{y}^{2} a_{w y}^{2}+k_{z}^{2} a_{w z}^{2}\right)^{\frac{1}{2}}
$$

where: $\mathrm{a}_{\mathrm{wx}}, \mathrm{a}_{\mathrm{wy}}, \mathrm{a}_{\mathrm{wz}}$ : weighted RMS accelerations along the $\mathrm{x}, \mathrm{y}$ and $\mathrm{z}$ axes; $\mathrm{k}_{\mathrm{x}}, \mathrm{k}_{\mathrm{y}}, \mathrm{k}_{\mathrm{z}}$ : indices the values of which were determined depending on the effects of the relative components of the acceleration on the health: for $\mathrm{k}_{\mathrm{x}} \mathrm{e} \mathrm{k}_{\mathrm{y}}$ a value of 1.4 is applied in the case of sitting positions, as they are equal to 1 for the upright position; $\mathrm{k}_{\mathrm{z}}$ is equal to 1 in both positions.

The exposure to the vibrations can be quantified by normalizing the value of the acceleration $a_{v}$, measured during the daily exposure time $\left(\mathrm{T}_{\mathrm{e}}\right)$, referring to a 8 hours time interval, according to the principle of "equal energy", providing the normalized acceleration, A(8) according to the formula:

$$
A(8)=a_{v} \sqrt{\frac{T_{e}}{8}}
$$

According to the standard ISO 2631-1, the calculation of A(8) aimed at the health risk assessment is made only considering the dominant axial $\mathrm{a}_{\mathrm{w}}$ component. Considering the particular characteristic of agricultural work, in which all the axial accelerations are often relevant, this study, also provided the calculation of $\mathrm{A}(8)$ as function of the resultant acceleration, $\mathrm{a}_{\mathrm{v}}$ and of the vertical weighted acceleration, $\mathrm{a}_{\mathrm{wz}}$, in order to observe how they affect the time of exposure. The determination of $\mathrm{A}(8)$ and the calculation of the maximum daily exposure times were made using the Excel data-sheet "Calculation of the exposure to vibrations" in the ENAMA website.

Tests - The tests consisted of transfer trials withour traction load (Figure 3) on asphalt track at $10.8 \mathrm{~ms}-1$ (39 km h-1), on a macadam

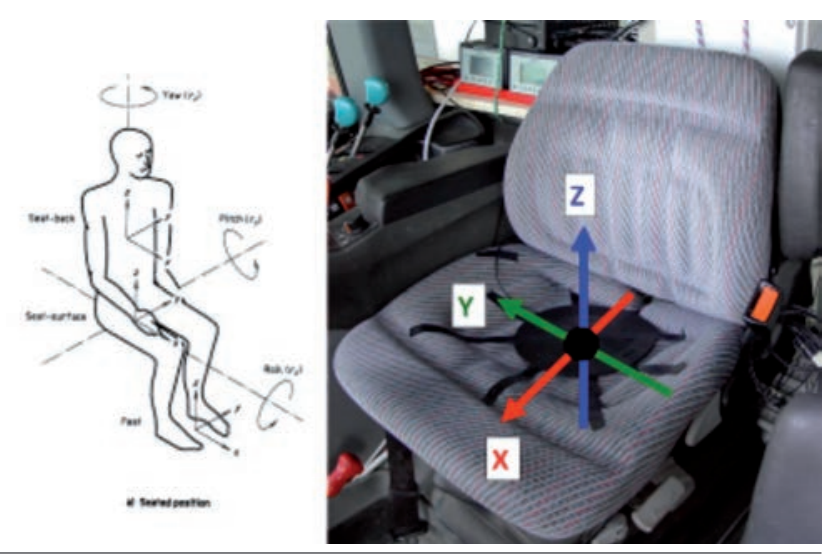

Figure 2. System of coordinates for the orientation of the accelerometer for seated operator and the driver seat with tri-axial accelerometer. 
road at $7.7 \mathrm{~ms}-1(27.7 \mathrm{~km} \mathrm{~h}-1)$ and on grassed headland at $4.5 \mathrm{~ms}-1$ (16.3 km h-1).

The gear box rations were chosen in order to achieve, on each surface, the highest travel speed. As a consequence, considering the available test distance on each surface, the sampling intervals meanly resulted of $13.8 \mathrm{~s}$ on asphalt, $19.5 \mathrm{~s}$ on macadam and $33.3 \mathrm{~s}$ on the headland. Three replications were made in each condition, comparing the measurements with the front axle suspension disconnected (thesis A) and connected (thesis B).

\section{Results and discussion}

The Table 1 and the Figure 4 show the results of the transfer tests on the three surfaces. In all test conditions, the values of $a_{v}$ increase passing from the frame of the tractor, to the cab floor, to the driver seat.

The amplification of the vibrations in the transition from one survey point another is related to the nature of the materials, to the constructive characteristics of the various elements, to the connections between them (geometries and characteristics of stiffness, etc..) and to the increasing distance from the points where the vibrations are generated and from which are transmitted (i.g. the contact area between tire and ground). This pattern was observed in all the theses and seemed more evident in the tests at higher speed (asphalt track and macadam).

From the observation of the axial components of the acceleration, $\mathrm{a}_{\mathrm{w}}$, (Table 1), it can be noticed that even in presence of a dominant component, the other two axial components often assumed relevant values.

In general, the peaks of the accelerations always occurred at low frequencies (between 1 and $3.15 \mathrm{~Hz}$ ). Significant examples of such patterns are shown in the diagrams of Figure 5, reporting the results of the frequency analyses of the weighted accelerations with reference to the axes $\mathrm{X}$ and $\mathrm{Z}$.

With reference to the three test surfaces, the following considerations can be made.

\section{Asphalt track}

The effect of the front suspension is more pronounced on the $\mathrm{X}$-axis (pitch) where a clear reduction occurs of the weighted average accelerations, $\mathrm{a}_{\mathrm{wx}}$ in the thesis $\mathrm{B}$ with respect to the thesis A (Table 1), on all three survey points (reduction from $39.83 \%$ to $48.57 \%$ ). In absolute terms the reduction was higher at the driver's seat level $\left(0,423 \mathrm{~ms}^{-2}\right)$.

This is confirmed by the analysis in frequency on $\mathrm{X}$ axis (Figure 5) which clearly shows that the linear reduction of the acceleration, $a_{x}$, is more evident in the range of frequencies between 1.6 and $4 \mathrm{~Hz}$ on all three observed points. Thereby, the suspension seems to also reduce

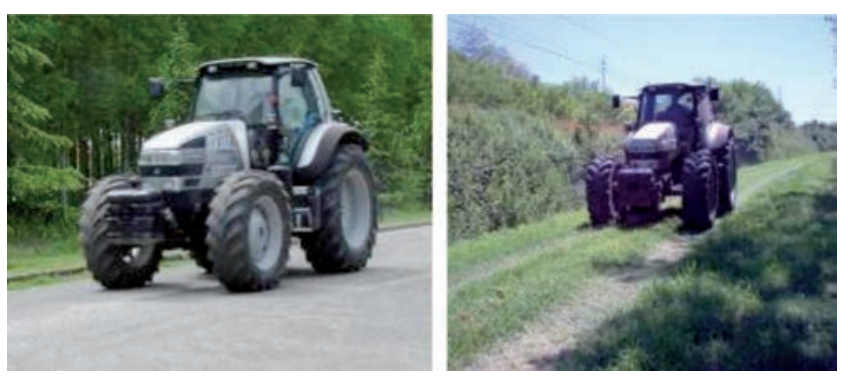

Figure 3. Tractor during the transfer tests on asphalt and on the headland.

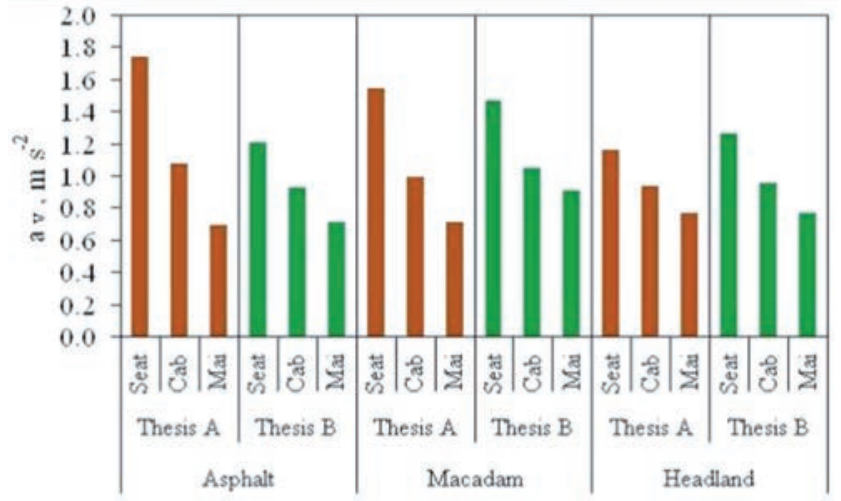

Figure 4. Average values of the vector acceleration, av, in the three point of application of the accelerometers.

Table 1. Values of the axial weighted accelerations aw, calculation of the resulting vector av, differences between the theses $A$ and $B$ in the different surfaces and values of the time of exposure. The time of exposure was calculated as function of the vertical acceleration awz $\left(\mathrm{Te}_{\mathrm{awz}}\right)$, of the vector acceleration $\mathrm{a}_{\mathrm{v}}\left(\mathrm{Te}_{\mathrm{av}}\right)$, and of the dominant wheighted axial acceleration $a_{\mathrm{wDom}}\left(\mathrm{Te}_{\mathrm{awDom}}\right)$. When the dominant axial acceleration is the $\mathrm{a}_{\mathrm{wz}}, \mathrm{Te}_{\mathrm{awz}}$ and $\mathrm{Te}_{\mathrm{awDom}}$ coincide.

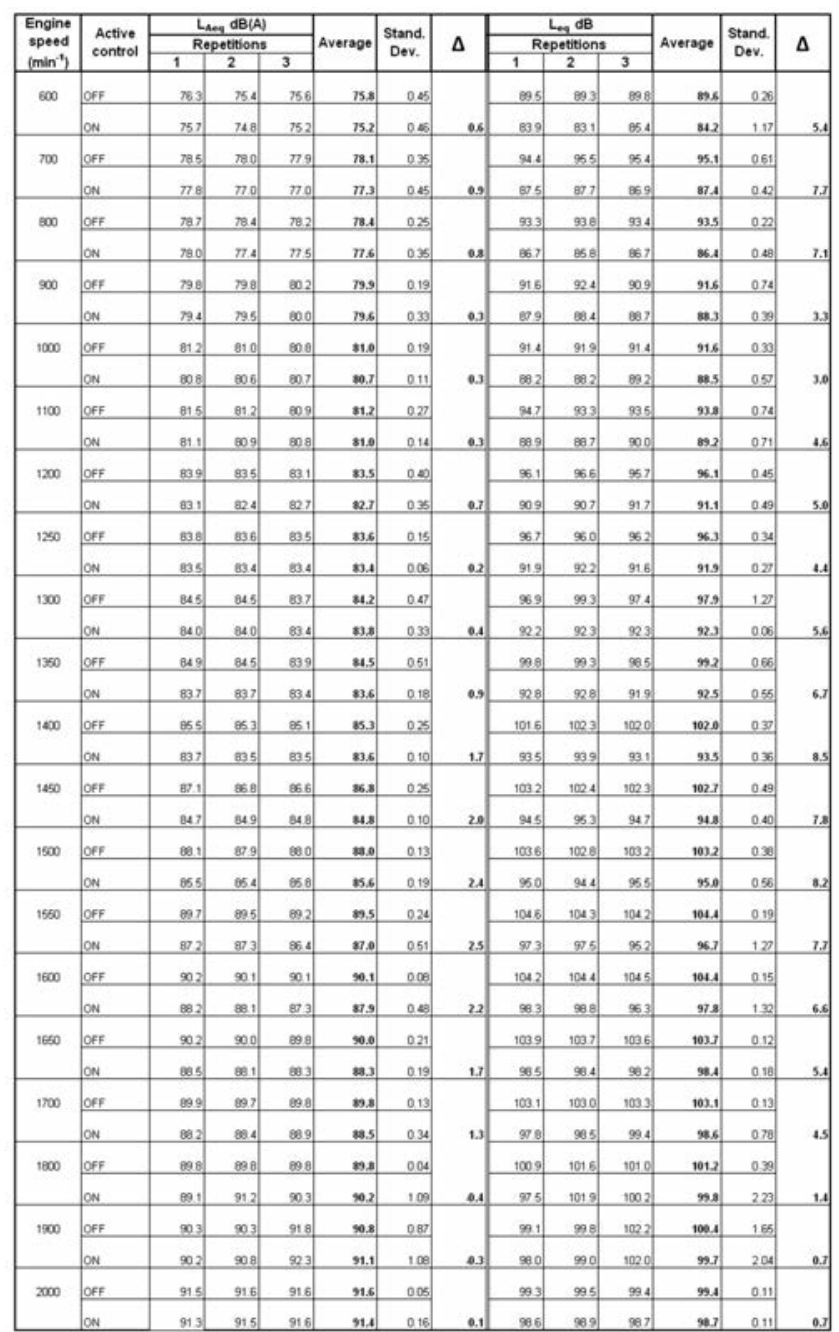


the level of vibration at the tractor mainframe. The effect of amplification of the vibrations, passing from the frame to the seat, is evident as well.

On the Y-axis (roll), the front suspension causes a worsening in the level of vibrations at the mainframe and improvements in cabin and seat.

About the Z-axis, despite $\mathrm{a}_{\mathrm{wz}}$ at the frame is higher for the thesis $\mathrm{B}$ (probably for effect of different surface irregularity in the two theses), a decrease of the vibration is detected specially at the driver seat, the shock absorber of which, combined with the front suspension, seems to increase its efficiency. Such a behaviour is visible in the diagram of the analysis in frequency (Figure 5) for frequencies between 3.2 and $20 \mathrm{~Hz}$, where $a_{z}$, for the thesis B is always less than for the thesis A.

\section{Macadam road}

Despite the lower forward speed, the stresses caused by this surface were more severe than by the asphalt, as evidenced by the values of weighted accelerations averages $\mathrm{a}_{\mathrm{wx}}$ and $\mathrm{a}_{\mathrm{wy}}$ on the frame, and from those of $\mathrm{a}_{\mathrm{v}}$ (Table 1).

Despite of the controversial behaviour of the axial weighted acceleration $\mathrm{a}_{\mathrm{w}}$ (Table 1), the thesis A presents higher values of $\mathrm{a}_{\mathrm{v}}$ at the frame and on the cab floor and lower at the driver seat, than the thesis B (Figure 4). The Z-axis resulted as the most stressed. The effect of the front suspension on the pitch (X-axis) can be observed in Figure 5. The linear acceleration, $a_{x}$, at the mainframe are similar for the two theses; passing at the driver-seat ax increases and is higher for the thesis $B$ in the interval 1,25 - $2 \mathrm{~Hz}$. The surface in macadam seems to produce shocks characterized by frequency values that tend to be lower than in asphalt and the evaluation of the effectiveness of the front suspension in such condition requires further tests.

The analysis in frequency on the Z-axis (Figure 5) shows that the linear acceleration is lower for the thesis $B$ in the interval $1.6-16 \mathrm{~Hz}$, with a relevant reduction on the peak point at $2.5 \mathrm{~Hz}$.

\section{Grassed headland}

The resultant acceleration, $a_{v}$, is higher for the thesis $B$. As to the weighted accelerations, the dominant aw occur on the Z-axis for the Thesis A and on the Y-axis for the thesis B. This variable pattern indicates that, differently from the asphalt, in the headland there is not a prevailing pitch effect. The relatively low speed and the characteristics of the surface (limited and variable transversal slope, unevenness and compactness softened by the grass) probably had a damping effect that interfered with action of the suspension.

As to the action of the front suspension against the pitch, the analysis in frequency (Figure 5) shows that the linear acceleration $a_{x}$ increases passing from the mainframe to the seat and that in the thesis $B$ it has lower levels than in A. The higher values occurred in the interval of frequency between 1.6 and $3.15 \mathrm{~Hz}$. The analysis in frequency on the Z-axis shows that the front suspension (thesis B) determines a reduction of the acceleration $\mathrm{a}_{\mathrm{z}}$ in the interval $3.15-4 \mathrm{~Hz}$, as it is increases in all remaining frequencies, with two relevant peaks a 2.5 and $8 \mathrm{~Hz}(\mathrm{~Hz})$.
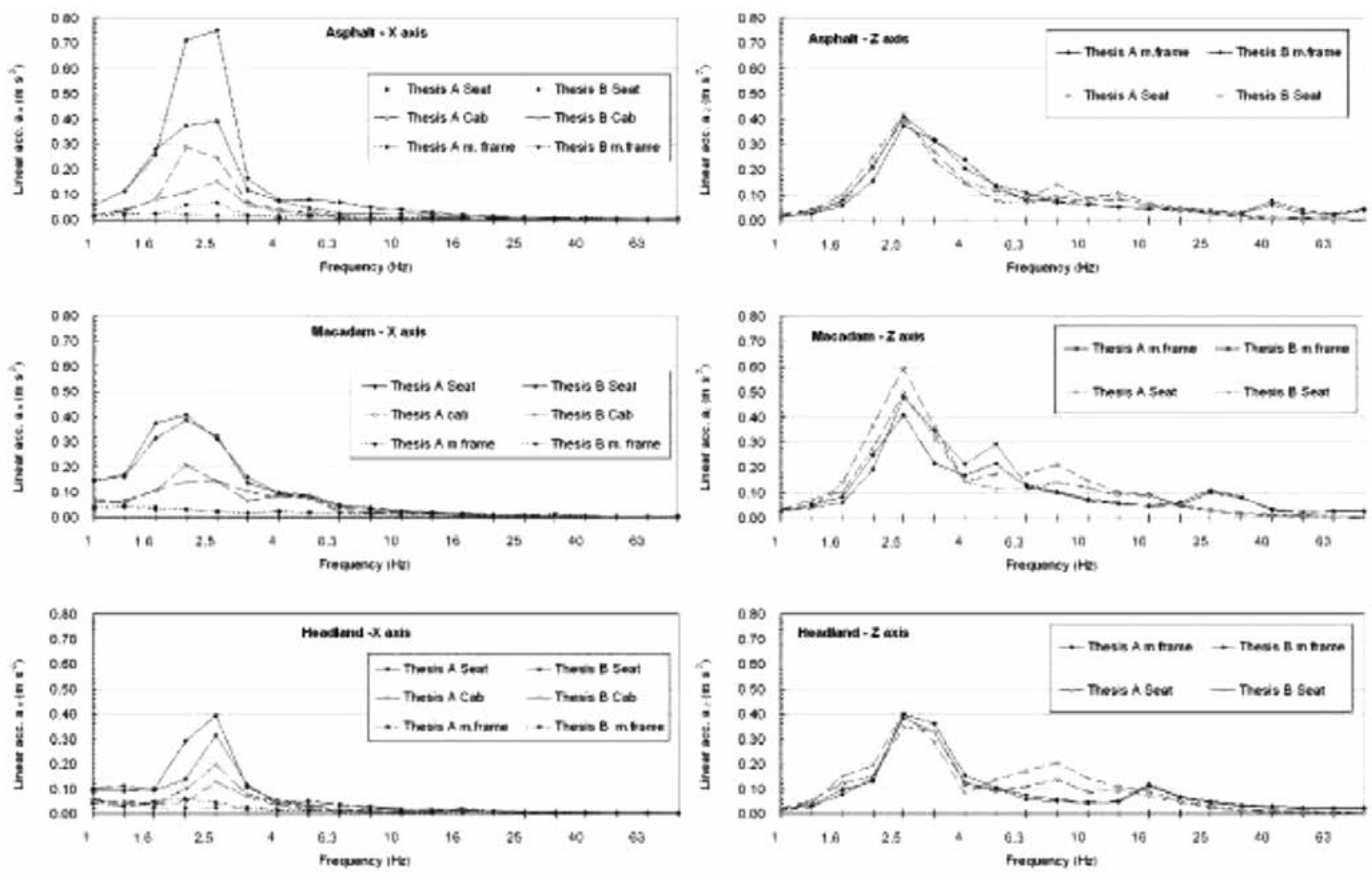

Figure 5. Frequency analysis of the accelerations during the transfer tests on the three surfaces with front axle suspension "off” (Th. A) nda and “on"(Th. B). Left: $\mathrm{X}$-axis $(\mathrm{aX})$ in the three points of observation. Right: Z-axis (aZ) only for the tractor mainframe and the driver seat, in order to achieve information about the shocks transmitted through the system by soil unevenness. 
Finally, the Table 1 reports the exposure times calculated by means of the relation (3) as a function of the dominant axial acceleration $\mathrm{Te}_{\text {awDom }}$, (according to the ISO 2631-1), of the resultant $\mathrm{a}_{\mathrm{v}}, \mathrm{Te}_{\mathrm{av}}$ and of the vertical component $\mathrm{a}_{\mathrm{wz}}, \mathrm{Te}_{\mathrm{awz}}$. The exposure times with the front suspension connected always resulted higher than suspension disconnected. Moreover, $\mathrm{Te}_{\mathrm{av}}$ evidently resulted with lower values in all the tests, which demonstrates the relevant influence of all axial components, as expected. In this regard, for instance, observing the $\mathrm{a}_{\mathrm{w}}$ values in Table 1 , on asphalt/Thesis $B$, the weighted axial acceleration values are $0.64 \mathrm{~ms}^{-2}, 0.40 \mathrm{~ms}^{-2}$ and $0.59 \mathrm{~ms}^{-2}$ respectively for $\mathrm{X}, \mathrm{Y}$ and $\mathrm{Z}$, as $\mathrm{a}_{\mathrm{v}}$ calculated with the relation (2) is $1,74 \mathrm{~ms}^{-2}$. The calculation according the reference standard should be made using the dominant $\mathrm{a}_{\mathrm{wx}}=0.64$ $\mathrm{ms}^{-2}$, ignoring $\mathrm{a}_{\mathrm{wy}}$ and $\mathrm{a}_{\mathrm{wz}}$, despite the values of the latter can be considered of the same order of magnitude of $\mathrm{a}_{\mathrm{wx}}$ and heavily affect the determination of the resultant acceleration vector $\mathrm{a}_{\mathrm{v}}$. Unlike other work environments, the solicitations typical of agricultural work evidently involve all the spatial components and, as a consequence, the application of the common concept of "dominant axial component" may be improper and may contribute to an underestimation of the risks from exposure to the vibrations.

\section{Conclusions}

The front axle suspension represents a contribution to the improvement of the working conditions of the drivers of agricultural tractors from the point of view of the comfort and health protection.

The device resulted effective in the absorption of shocks and vibrations (mostly the pitch), due to the unevenness of the road surface. The best performances were observed in the tests at higher speeds and were confirmed by the impressions of the operators about an increased level control of driving. The increases of the time of exposure testifies the improvement of the quality of the working conditions. Such results are relevant with reference to the increasing importance of the road transfer operations, also considering the tendency to raise the speed limits for the tractors.

The effectiveness of the device is less evident at lower speeds and on more irregular surfaces, where, at any rate, its positive effects continue on the Z-axis, enhancing the action of the seat suspension.

\section{References}

Decreto Legislativo 9 aprile 2008, n. 81 Attuazione dell'articolo 1 della legge 3 agosto 2007, n. 123, per il riassetto e la riforma delle norme vigenti in materia di salute e sicurezza delle lavoratrici e dei lavoratori nei luoghi di lavoro, mediante il riordino e il coordinamento delle medesime in un unico testo normativo, G. U. n. 101 del 30 aprile 2008.

IS0. 1997. Mechanical vibration and shock - Evaluation of human exposure to whole-body vibration - Part 1: General requirements (ISO 2631-1:1997). International Organisation for Standardisation (ISO), Geneva, Switzerland.

Produzione documentale tecnica sulla problematica delle vibrazioni connessa all'uso delle macchine agricole ENAMA - Roma 2005. www.Enama.it

Pochi, D., Vassalini G., Fornaciari L., Gallucci. F. 2006. Valutazione delle vibrazioni trasmesse all'operatore da una trattrice a cingoli in varie condizioni di utilizzo. In Proc. dB(A) 2006 Rischi fisici negli ambienti di lavoro - Volume 1: Rumore e vibrazioni, Modena, Italy, 12-13 0ctober.

Nuccitelli G., Ragni L. 1993. Influence of seat adjustment on the vibrations transmitted to the driver. Journal of Agricultural Engineering, 3: 143-150.

Fornaciari L., Pochi D., Vassalini G., Gallucci F. 2008. "Investigation of the vibrations transmitted by agricultural tractor to the driver under operative conditions" - International Conference: September 15-17, 2008 Ragusa - Italy.

Pochi D., Vassalini G., Fornaciari L., Gallucci F. 2007. "Hand-arm vibration levels measured under operating conditions in different types of agricultural tractors" - 11th International Conference on Handarm Vibration - 3-7 june 2007, Bologna.

Vassalini G., Fornaciari L. 2007. "Valutazione del rischio vibrazioni del parco macchine dell'azienda sperimentale del CRA-ISMA con il D. Lgs. 187/05" - Atti del $13^{\circ}$ Convegno di Igiene Industriale - Le giornate di Corvara - 26-28 marzo 2007.

Pochi D., Vassalini G., Fornaciari L., Gallucci F. 2006 "Valutazione delle vibrazioni trasmesse all'operatore da una trattrice a cingoli in varie condizioni di utilizzo" - $\mathrm{dB}(\mathrm{A}) 2006$ Rischi fisici negli ambienti di lavoro - Volume 1: Rumore e vibrazioni.

Scarlett, A. J., J. S. Price, and R. M. Stayner. 2007. Whole-body vibration: evaluation of emission and exposure levels arising from agricultural tractors. Journal of Terramechanics, 44: 65-73. 